\title{
A “EXPOSIÇÃO” AO NOVO E O PROCESSO DE "SER" HUMANO NO CONSTITUCIONALISMO CONTEMPORÂNEO: DA “CAVERNA" DE PLATÃO AO “QUARTO DE JACK”
}

\author{
AN "EXPOSITION" TO THE NEW AND THE PROCESS OF \\ "BEING" HUMAN IN CONTEMPORARY CONSTITUTIONALISM: \\ FROM THE "CAVERNA" OF PLATÃO TO "JACK'S ROOM"
}

\author{
Natercia Sampaio Siqueira \\ Camilla Martins Cavalcanti
}

\section{RESUMO}

0 artigo trata do efeito da "exposição" ao processo de "ser" humano. Parte-se da hipótese de que a exposição ao novo é elementar ao desenvolvimento cognitivo e afetivo humano, necessário para que as potencialidades de "ser" humano sejam vivenciadas. Utiliza-se da análise tanto da narrativa filosófica, como cinematográfica acerca da exposição: primeiramente, analisa-se o mito da caverna, exposto por Platão em à República; no segundo momento, detém-se na película "O quarto de Jack". Conclui-se que o "novo" é fundamental à cognição e aos afetos da criança e do adolescente e que deve ser objeto de políticas públicas.

Palavras-chave: 0 processo de "ser" humano. Criança e adolescente. Mito da caverna e o quarto de Jack. 


\section{ABSTRACT}

The article deals with the effect of "exposure" to the process of "human being". It is hypothesized that exposure to the new is elementary to human cognitive and affective development, necessary for the potentialities of human "being" to be experienced. It uses the analysis of both philosophical and cinematic narrative about the exhibition: first, the cave myth, exposed by Plato in the Republic; in the second moment, it stops in the film "Jack's room". It is concluded that the "new" is fundamental to the cognition and affects of children and adolescents and should be the object of public policies.

Keywords: Human "being" process. Child and teenager. Cave Myth and Jack's Room.

\section{INTRODUÇÃO}

De nítida herança Kantiana, o Direito, em grande parte do mundo ocidental da atualidade, possui na dignidade humana seu principal propósito e condicionamento. 0 Estado toma para si, não apenas, deveres de abstenção, mas de prestação, de maneira a se efetivamente assegurar uma vida digna ao homem. Neste propósito, vários elementos, presentes em uma longa tradição filosófica, são almagamados: igualdade, liberdade, capacidades, desenvolvimento.

Mas não se pode olvidar que referido projeto pressupõe a adoção de um determinado processo ou de uma certa dinâmica do que é "ser" humano, de maneira que vala à pena. Neste artigo, propõe-se uma dimensão que se considera essencial para o processo do "ser" humano: a exposição, não apenas cognitiva, como afetiva; não apenas intelectual, como sensitiva.

Referida questão, por outro lado, é implícita ou mesmo explícita ao pensamento de nomes conhecidos na história do ocidente. Mas a "exposição" assume, no presente trabalho, o caráter elementar ao projeto de uma narrativa de vida digna. É este o problema central do artigo: analisar a relação entre os processos de exposição e de uma vida digna, posto que valha à pena ser vivida. Para tanto, opta-se por trabalhar a temática mediante duas narrativas concretas, não obstante diversas: o mito da caverna de Platão e o filme "O quarto de Jack", a primeira a trabalhar o aspecto epistemológico da exposição e o segundo a explorar, 
multidimensionalmente, os impactos nas diversas ordens existenciais que a exposição causa ao indivíduo.

Em relação aos aspectos metodológicos, a pesquisa é bibliográfica, pois foi fundamentada por meio de estudos de obras literárias, bem como de dissertações e artigos científicos que versam sobre os temas relacionados a pesquisa. Quanto ao método, tem-se o dedutivo, tendo em vista o fato de ser o método lógico que pressupõe que verdades gerais funcionam como premissa para serem criados novos conhecimentos. No que diz respeito à utilização dos resultados, é pura, pois será realizada com a finalidade de aumentar o conhecimento do pesquisador. $\mathrm{E}$ a abordagem é qualitativa, exploratória, e descritiva.

Pela justificativa metodológica ao presente artigo, abordar-se o Mito da Caverna de Platão, no contexto em que foi tratado na República. Depois, é realizada a narrativa do filme "O quarto de jack" inspirado no livro "Quarto" Emma Donoghue, para, em um terceiro momento, assinalar as similitudes entre as duas narrativas. Desta comparação, extraem-se os efeitos da exposição ao processo do "ser" humano, para a partir deste dado enfocar as políticas públicas de educação e proteção à criança, ao adolescente.

Ao final, adverte-se sobre o paradoxo da dignidade em uma democracia, que compartilha uma dimensão material e outra formal. A dimensão material da dignidade, a se realizar pelas funcionalidades que se deve minimamente assegurar para que uma pessoa possa desenvolverse na sua história de vida e posicionar-se equanimemente na dinâmica social, testa os limites da dimensão formal, que abraça a perspectiva de que as pessoas são substancialmente livres para traçarem seus objetivos.

Portanto, o artigo está assim estruturado: considerações iniciais, seguida dos quatro seguintes capítulos: A Alegoria da Caverna de Platão; O Filme O Quarto de Jack; Os pontos comparativos entre o a Alegoria da Caverna de Platão e o Filme 0 Quarto de Jack; A exposição como política pública: o paradoxo da democracia, e encerra-se com as considerações finais. 


\section{UM MÉTODO DELICADO}

Preliminarmente, cabe ressaltar que alguns temas são longevos e mereceram diferentes narrativas, seja pelas artes, pela ciência, pela filosofia. Questionar sobre a perenidade e os vários interesses que alguns temas suscitam já é uma questão interessante; talvez assim o sejam por estarem associados a características e condicionamentos do processo que é o "ser" humano, em sociedade ou consigo próprio.

Ao se deparar com tais assuntos, uma metodologia estimulante consiste em analisá-los através das variadas narrativas das quais foram objetos: cada narrativa explora diferente aspecto humano e abordá-las em conjunto pode muito bem propiciar um entendimento mais complexo, não apenas sobre o assunto cogniscível, mas sobre o homem cognoscente. Veja-se, por exemplo, o caso da agência: é tratado pela filosofia, pela neurobiologia, pela psiquiatria, pela psicologia, pela arte. E enquanto as primeiras linguagens esforçam-se na coerência e objetividade, a segunda sente-se livre para explorar as emoções e as complexidades humanas; em conjunto, o racional e o sensitivo que informam a cognição humana.

Por esta tratativa animou-se Martha Nussbaum (2009), em seu livro a Fragilidade da Bondade. Nele, abordou temas da ética, como o vulnerabilidade ao contingente e a responsabilidade, pela escrita de filósofos e poetas gregos. Ao contrastar uma linguagem com a outra, comenta Nussbaum no Prefácio do seu livro "A Fragilidade da bondade": "No entanto, pode acontecer de a insatisfação com a teoria ética moderna conduzir o pensador não aos filósofos, mas às intuições da literatura grega pré-platônica sobre a fortuna e a vulnerabilidade". Posteriormente, ainda por ocasião do prefácio, ressalta:

[...] Dado que as coisas valiosas são Plurais e irredutíveis a alguma coisa valiosa e única da qual todos os outros bens seriam meras funções, os agentes morais se tornam vulneráveis à fortuna de um segundo modo, uma vez que pode haver conflitos contingentes de valor que tornem difícil ou mesmo impossível para eles cumprir todas as coisas com as quais se comprometeram. As tragédias proporcionam ricos estudos sobre esses conflitos; mas argumentei que o pensamento de Aristóteles - apesar, 
novamente, de se Reocupar com a harmonia em um grau mais elevado que os poetas trágicos 'também lhes abre espaço.

A harmonia e coerência podem mostrar-se como linguagem por demais redutora e formal da natureza humana, de maneira a soar insatisfatória, ainda quando se pretenda uma narrativa científica ou técnica. Daí Nussbaum ter explorado a linguagem poética e da filosofia grega sobre um mesmo tema. Por se considerar válido referido experimento metodológico, as autoras se propuseram a adotar uma mesma questão sob o enfoque da epitemologia platônica e do cinema contemporâneo: o desenvolvimento humano pela "exposição" a outras realidades, exteriores e mais abrangentes, como um mundo em camadas de cebola que se vai descascando de dentro para fora.

Ao tratar a mesma questão utilizando-se da narrativa de "A República" e de "O quarto de Jack", pretende-se, pelo rigor da linguagem científica e pela liberdade da linguagem artística examinar o efeito da exposição ao novo sobre o desenvolvimento humano, de maneira a se trabalhá-la como elemento constitutivo da dignidade humana que deva ser objeto de políticas públicas. Começa-se, a empreitada, por Platão.

\section{A ALEGORIA DA CAVERNA DE PLATÃo}

Especificamente em Platão, se aborda a Alegoria da Caverna, presente no livro A República, que foi escrito por volta do ano de 380 a.C e que é o produto da reação de Platão à morte de Sócrates. A república é dividida em dez livros, construídos na forma narrativa de um diálogo entre Sócrates e outros personagens conhecidos no debate filosófico grego, Céfalo, Trasímaco, Glauco, Adimanto, Nicerato, Polemarco e Lísias.

Ana Alice Miranda Menescal (2009, p. 69) chama a atenção para o fato de que no Livro A República, Platão empreendeu, por meio de uma linguagem filosófica, a análise sobre a formação do Estado ideal e as ferramentas fundamentais para o "bom convívio na pólis". Um dos grandes objetivos da República seria a constituição do modelo ideal de uma cidade, o que envolveu a incursão, por Platão, como destaca a autora, 
em três temas: a Política, a Ética e a Cidadania (MENESCAL, 2009, p.44). Pode-se ainda evocar, a epistemologia.

Homem e cidade são realidades que servem de metáfora uma a outra e que reforçam a compreensão mútua. Tratando do conhecimento humano, Platão aventura-se na elaboração do modelo de uma cidade justa, plena, harmoniosa. Ou seja, da cidade ideal. O filósofo grego elege a racionalidade como instrumento necessário e único ao conhecimento da ideia: o conceito verdadeiro das coisas. Pela racionalidade, se faz a ascese da manifestação sensível, por natureza parcial e incompleta, da coisa, ao seu conceito verdadeiro, posto que completo, o que permite o conhecimento do bem em todas as suas manifestações sensíveis, portanto incompletas. A fortuna está na completude da ideia, que liberta o homem do contingente, pois o municia para encontrar o bem nas suas variadas existências sensíveis.

Se à razão, que é o elemento da alma apto a ascese, ou seja, ao conhecimento da ideia, deve caber as decisões sobre a vida da pessoa, por analogia ao filósofo, homem por natureza apto à racionalidade, deve caber o governo da cidade. Neste ponto, delineia-se o estreito vínculo entre política, cidadania e epistemologia platônica: a cidade justa é aquela governada de acordo com a verdade, o que implica o governo pelos filósofos, que seriam as pessoas com aptidão ao conhecimento da verdade. A República, que é o segundo diálogo mais extenso de Platão, carrega no caráter político da narrativa dialógica, expondo a utopia platônica.

Mas o livro, ainda quando avança pela construção de um modelo político ideal para a pólis com fundamento na ética, assim o faz mediante é importante que se ressalte, uma vez mais - o investimento epistemológico na racionalidade, apta ao alcance da verdade. A epistemologia é tratada por referências dicotômicas entre racionalidade e sentido, com o descrédito do último: pela racionalidade se alcança a verdade, ao passo que os sentidos apenas permitem a apreensão incompleta do bem e, por isto mesmo, falha.

Para explicar esta realidade, Platão trabalha a metáfora da Caverna, presente no Livro VII da obra A República, na qual homens, durante boa parte da vida ou, pelo menos, desde a infância, estiveram presos em uma caverna. Estes homens foram presos com o pescoço e as pernas de tal forma arranjados que só tinham a opção de olhar para a parede oposta à 
abertura da caverna, pela qual permeava a luz de uma fogueira acesa no seu exterior. Desta forma, a única realidade conhecida pelos prisioneiros consistia nas sombras projetadas na parede das imagens exteriores à caverna, assim como os ecos das vozes. 0 conhecimento era limitado, parcial, por conseguinte, falho. Não obstante, se os prisioneiros fossem soltos e obrigados a olhar as coisas, quando diretamente iluminadas pela luz solar e não através da projeção de suas sombras, eles as conheceriam na sua realidade, completude e, por consequência, alcançariam a verdade. Mas não necessariamente ficariam felizes; o processo do conhecimento da realidade seria difícil e iria requerer um esforço grande, pois não mais se conseguiria reconhecer os objetos refletidos (PLATÃO, 2007, p. 315-316).

Pode-se dizer que, ao estarem aprisionados na Caverna, desde a fase infantil, a luz refletida seria a realidade conhecida por eles, uma vez que impossibilitados de olhar para trás. Tudo o que podiam enxergar era o refletido na parede e o que podiam ouvir eram os sons que ecoavam das sombras. Ou seja, as sombras e os ecos, por serem tudo o que naquelas condições seus sentidos permitiriam conhecer, seria para eles a realidade. 0 que se vê é o que é real quando só se tem isso.

Porém, ao serem conduzidos à saída da caverna, de imediato o liberto iria sofrer em razão do contato direto com a luz solar, e ainda que em condições do pleno conhecimento da realidade, de início se irritaria; a claridade da luz lhe dificultaria o reconhecimento do real. Mas, após se acostumar com as novas condições de iluminação, conseguiria destingir as coisas e perceber que o que via na caverna era apenas o reflexo. Ele se apropriaria do conhecimento da realidade, de maneira que passaria a menosprezar o conhecimento reduzido e parcial que tinha das coisas na caverna. No fim da alegoria, Platão considera que se o homem, que teve a oportunidade de ser liberto, voltasse para o interior da caverna, ele seria rejeitado pelos prisioneiros ali residentes e, caso tentasse tirá-los daquela condição de aprisionamento, correria o risco de, inclusive, por eles ser morto. (PLATÃO, 2007, p. 315-317).

A prisão, tendo sido imposta desde cedo na vida dos prisioneiros, só lhes possibilitou o conhecimento parcial que, para si, seria a própria realidade. E esta seria a maior prisão a qual se poderia submeter: a prisão 
no mundo visível, ou seja, à perspectiva reduzida dos sentidos. Não poderia ser mais direta a analogia entre o mito da caverna e a morte de Sócrates.

Neste tocante, Daniela Martins Madrid (2012, p. 4-5) frisa que as imagens refletidas, por serem as únicas coisas passíveis de serem enxergadas, eram concebidas como verdades inabaláveis. Para a autora, o mundo tido como o das sombras não configurava tão somente à escuridão, mas à ignorância, porque quando só lhe é dado uma visão distorcida não se pode cobrar mais do que isso e, então, ela será a verdade de quem só a ela detiver. E ainda por crerem que a sombra materializasse a realidade da coisa não se tinha o desejo de procurar qualquer outro conhecimento sobre o que existia fora da caverna, afinal, aquela verdade já lhes bastava.

Na própria “República”, Platão (2007, XXVIII) explicita a correspondência entre o mundo visível à caverna e o inteligível à ascese: "[...] Mas a continuação explicita que se deve comparar o mundo visível à caverna e o inteligível à ascensão dos prisioneiros ao mundo superior. ” O mundo cognoscível pelos sentidos é o mundo da caverna, já o mundo inteligível em sua realidade é o do exterior; o mundo superior, da verdade.

Como comenta Antônio José V. de Queirós (2008, p. 96-97), a ascensão da alma ao mundo exterior configuraria a chegada na esfera inteligível. A ênfase na alegoria da caverna à questão das sombras e da luz simboliza, respectivamente, as dimensões da aparência e o da realidade, sem deixar de ressaltar a comunicação entre o mundo da caverna e o mundo inteligível, a ponte que existe entre ambos, já que os objetos que são refletidos no interior da caverna pertencem ao mundo superior/exterior.

O plano sensível, ou seja, o plano do que se pode ver, é diferente do plano inteligível, no qual chegará à definição do belo; o conhecimento máximo como a ideia do bem e o sol como o filho do bem (MARSOLA, 2017). Na esfera inteligível, chega-se à verdade, ao conhecimento da realidade e, nisso, consiste a ideia do belo como sendo real. E o critério de que o conhecimento é relacionado ao bem também tem relação com a verdade, com aquilo que se pode conhecer. 0 sol é o filho do bem, é quem emite a verdadeira luz, o conhecimento; não é apenas uma luz refletida.

Platão, é claro, desenvolve uma filosofia que segrega a verdade da opinião, que leva o filósofo ao isolamento: não há diálogo possível entre o que retorna do exterior e os que permanecem aprisionados na 
caverna. A interação, as trocas, não são mais passíveis de tomar lugar no convívio social, o que leva ao medo. Aqui, é poderosa a intuição de que a incompreensão leva ao medo; é como Martha Nussabaum (2013, p. 2) tenta explicar os extremismos no discurso político contemporâneo entre esquerda e direita.

Mas em seu momento intermediário, Platão, afeiçoado às dicotomias e negando a possibilidade de interação entre verdade e opinião, recorre à submissão: a temperança como a virtude das partes de se manterem no lugar que lhes é devido em razão da sua natureza. Em uma cidade justa, não apenas os filósofos governam, como os que não são filósofos aceitam esse governo e se mantêm por ele governados. Não é necessário que os filósofos convençam os não filósofos; antes, eles aceitam, aprioristicamente, a aptidão daqueles para conhecer e, portanto, para o melhor governo da cidade. Aqui, o pessimismo platônico quanto à prática dialógica: ela não é possível entre os que conhecem e os que não conhecem e a racionalidade daqueles que não são aptos a conhecer limita-se a aceitar que os que conhecem devem governar.

A par dessa configuração negar a política, como bem expõe na "Promessa da política" Hannah Arendt (2008), o mito da caverna, com seus elementos, forte simbolismo e expressiva narrativa literária, convida para se pensar sobre a exposição a uma nova perspectiva, de alguma forma mais ampla e informada que a anterior, que muda a pessoa, a leva ao estranhamento próprio e alheio, para ao final ampliar suas compreensões e entendimentos, agregando-lhe algo a mais poderoso, que a torna melhor. Ainda que pela perspectiva racional e antropológica, o exercício da inquietação perscrutadora, que leva a novos mundos, a uma nova dimensão, ao "bem". É um imperativo do desenvolvimento da natureza humana, expor-se, para chegar ao "bem".

Por uma perspectiva axiológica, até mesmo ontológica e pessoal, o mito da caverna traz luz ao poder de uma nova dimensão. Mas o fez, é importante que se ressalte, pela perspectiva epistemológica: o foco é o atingimento da verdade pela racionalidade. Já nesse tópico, entretanto, procurou-se ampliar a metáfora da caverna para amoldá-la a uma hipótese mais abrangente: ao conhecimento (seja para os que guardam a perspectiva ontológica, seja para os que não se mostram ansiosos à distinção entre 
realidade e opinião), é preciso a exposição a diferentes dimensões e perspectivas. Expor-se a novas luzes, buscar o exterior de si, sair do paradigma em que se vive, é o desafio do conhecimento pelo qual as ciências, durante os séculos, aventuraram-se.

Mas na República, no momento é importante que se frise, a ênfase é na epistemologia: a racionalidade seria o elemento - tanto mais apropriado quanto depurado dos sentidos - da alma humana que possibilitaria chegar à verdade mediante o conhecimento da ideia. Os sentidos, na concepção de Antônio Damásio (2017, p. 48), não serviriam à cognição, o que hoje é negado pela neurociência, que ressalta a conexão entre sentidos e racionalidade: ausentes os sentidos, sequer se poderia comparar o homem à inteligência artificial, uma vez que sem o estímulo e motivação daqueles a racionalidade funcionaria de forma penosa e lenta. As dimensões, racionais e sensitivas, se comunicam e explorá-las permite uma experimentação mais completa das coisas e de si.

Desta forma, se a exposição a novas dimensões, a novos contextos e condicionamentos de conhecimento, é necessária a cognição, também o é a exposição a novas pessoas, relações afetivas. 0 avanço na cognição dá-se pelo avanço no catálogo emocional: novos conceitos, para serem apreendidos, não raro estão a depender de novas vivências. No propósito da demonstração do referido vínculo entre exposição cognitiva e afetiva, é que se dedica a analisar o filme "O Quarto de Jack".

\section{O FILME “O QUARTO DE JACK”}

O Filme o Quarto de Jack é um drama que teve embasamento no romance da irlandesa Emma Donnoghue e que por ela foi adaptado. 0 filme é dividido em dois momentos: o primeiro, mostra o período do confinamento de uma mulher sequestrada desde a adolescência, com o filho que teve do sequestrador, em um quarto; é o único espaço que eles têm. Já, o segundo dá-se a partir da fuga que a jovem trama com o seu filho que, até então, mesmo que já com cinco anos de vida, não imaginava que existisse nada real além do quarto e das coisas que nele continham (ORTEGA, 2016, p.7-8). 
De forma introdutória, pode-se resumir o enredo do filme da seguinte forma: uma jovem de apenas 17 anos, chamada Joy, é abordada por um homem, que lhe pede ajuda, pois estaria com um cachorro doente. Ao atender ao pedido de ajuda, a jovem acaba sendo raptada e é confinada, pelo seu sequestrador - que dela abusa continuamente - em um quarto, cujo acesso dá-se mediante uma senha para entrada e saída. Assim, durante 7 anos, esse cenário se perpetuou, agravando-se com a gravidez da jovem. E, assim, nasceu Jack que, no período retratado pelo filme, acabara de completar cinco anos (O QUARTO... 2016).

A mãe, neste contexto, agarra a opção de fantasiar ao filho um mundo que se limita ao quarto em que se encontram aprisionados: o armário, a televisão, o tapete e uma claraboia. Constrói as relações da criança com o "mundo" mediante os objetos presentes no quarto, manipulando-o quanto às dimensões possíveis do real. Ou seja, tomava cuidado para que seu filho não percebesse que havia uma dimensão do real bem mais ampla do que a do quarto e, desta forma, não sofresse pela frustração que adviria do aprisionamento (O QUARTO... 2016).

Assim, o mundo de Jack era o quarto; o real era construído pelas coisas que lhe eram ditas pela mãe. Inclusive, durante boa parte do filme, o garoto não sabe se o sequestrador, conhecido por ele como o "velho nick", seria real, já que a sua mãe o trancava dentro do armário para que não tivessem contato. No quarto, Joy e o filho faziam exercícios, alongamento. 0 contato com cada objeto era relevante, um mundo e uma rotina feita de minúcias, miudezas, em que se tinha de obter sentido das poucas coisas, dos pequenos gestos, dos rotineiros contatos e afetos. Era esse o mundo de Jack (O QUARTO... 2016).

Mas na realidade de confinamento retratada no filme, não apenas o espaço, objetos e pessoas eram sonegadas, como a própria alimentação e cuidados básicos. Joy cobrava do sequestrador melhorias quanto a vitaminas, remédios, alimentação. A energia fora cortada, o sequestrador falava de dificuldades financeiras, o que avolumava o receio de Joy quanto à situação de vulnerabilidade do Filho. No entanto, o medo atingiu seu máximo grau quando o sequestrador, finalmente, vê Jack, o que sugere a manipulação do sexo da criança pela mãe, que assim o teria feito para evitar que fosse abusado (a) sexualmente pelo velho Nick. Quando os dois 
se veem, Joy decide que está na hora de "Jack" fugir. Neste momento, que se dá por volta de $26^{\circ}$ minuto do filme, Joy começa a contar para Jack sobre as outras dimensões, sobre o mundo que havia exteriormente ao quarto, exemplificando pelo rato que ali aparecera e estava do outro lado da parede. Além disso, ela começa a falar que as imagens da televisão eram reais ou correspondiam a coisas reais, que existiam fora do quarto (O QUARTO... 2016).

Para Jack, o conhecimento da realidade foi, no mínimo, assustador, pois entender que tudo aquilo que ele tinha como realidade era apenas uma perspectiva reduzida do mundo, não foi fácil. Mas, depois do seu momento de revolta, aceitou a verdade. Até que Joy começa a preparar um plano de fuga, no qual ele iria fingir que estava doente, com febre, de maneira que o sequestrador o levasse ao hospital. A criança, no entanto, levaria consigo um dente da mãe para provar a veracidade da história que contaria. Porém, o plano não deu certo, uma vez que o sequestrador não aceitou a ideia de levar o menino para o hospital. Nisto, Joy precisou ser rápida para adaptar o plano: ela decidiu que contaria que Jack tinha morrido para que o velho Nick o levasse enrolado em um tapete para ser enterrado. A ideia era que no meio do caminho o menino se desenrolasse do tapete, pulasse da camionete e contasse sua história a alguém, informando o nome da mãe e apresentando o seu dente (O QUARTO... 2016).

O desespero tanto da mãe quanto do filho no decorrer do plano de fuga mostra o quanto tinha de risco na sua execução. Quando Jack consegue se desvencilhar do tapete e saltar do carro, ele é descoberto pelo Velho Nick, que o persegue. No entanto, Jack encontra a ajuda de policiais. Ainda que desnorteado, consegue narrar a sua história, que mereceu o crédito dos interlocutores. A policial, de imediato ao resgate, busca com Jack o local em que sua mãe poderia estar confinada. Para tanto, pede que o menino lhe descreva seu quarto. Quando lhe pergunta o que tem do lado de fora, ele responde que o espaço, mas, em seguida, se corrige ao dizer: o mundo (O QUARTO... 2016).

A verdade é que, apesar de todo o despreparo de Jack com relação ao seu primeiro contato com o mundo, ele auxilia bem a polícia no resgate de sua mãe ao relatar das vezes que o carro parou, quando se aproveitava para se desprender do tapete e saltar, bem como ao falar da claraboia. Após isso, 
Joy é resgatada e se encontra com seu filho. Os dois vão para o hospital, onde receberam as preliminares do tratamento físico e psicológico. Afinal, não era só o grande lapso de tempo em que não eram expostos à luz do sol, do que decorriam as imunidades baixas. Havia toda a questão psicológica e emocional, cada um na sua peculiaridade.

O começo da segunda parte do filme, que se dá após o resgate de Joy e de Jack, mostra as dificuldades, de ambos, na adaptação à nova realidade, porque, mesmo Joy, teve seus problemas ao regressar ao mundo da qual fora subtraída. Afinal, ela era uma adolescente, que tinha sonhos, problemas, amigos e rotina como qualquer outra garota de 17 anos, mas que teve a sua vida interrompida em razão do sequestro que, além da restrição de ir e vir, a expôs a abusos sexuais constantes, à maternidade forçada, a dor e a privações. 0 rapto a retirou da rota "normal" que esperava, como qualquer garota de 17 anos, branca, de família de classe média Norte-americana, seguir: faculdade, namoros, emprego, casamento. O sequestro, ao lhe abduzir do seu mundo para expô-la a um outro, de violência, a estraga para o mundo que conhecia. Ela adquiriu uma nova perspectiva de vida que a desabilitou para a outra que tinha.

Já Jack teve dificuldade na comunicação com as outras pessoas. Ele, continuamente, buscava a confirmação da mãe para responder a algum questionamento, tanto que, em um dado momento, Joy o autoriza a responder a sua avó diretamente, para que ele se acostumasse à comunicação, pois o mundo dele não se resumia mais só a ela. 0 mundo de limites, minúcias e restrições é substituído por um mundo sem limite dimensional, em que uma porta (do quarto) abre para outro aposento (sala ou cozinha), cuja porta abre para um outro espaço (jardim ou quintal), que também contém uma porta que se abre a um espaço diferente (rua), do qual se sai ao transpor uma porta para um novo quarto.

0 que se pode dizer é que a liberdade, mesmo com o seu lado positivo, trouxe novos problemas, tanto em relação a adaptação de mãe e filho à nova realidade, como dos que "ficaram" ao regresso deles. É o caso do pai de Joy, que não conseguiu se relacionar com Jack em razão de ele ser filho do sequestrador. A imprensa e a repercussão do caso, a curiosidade das pessoas do mundo "real" ou "normal" em relação aos que chegavam de um mundo "irreal" ou "anormal", não permitiram à 
mãe e ao filho o tempo necessário para que se recuperassem e (re) adaptassem. Quando Joy decide gravar uma entrevista, a repórter acaba sendo invasiva, ao questioná-la se o que ela fez teria sido o melhor para o seu filho, o que a afeta profundamente e a leva a tentar o suicídio, que teve por consequência a sua internação.

Durante o período de internamento de Joy, Jack faz tratamento psicológico, estreita os laços com a família e aproxima-se do cachorro do marido da avó. Novas significações e afetos vão franqueando a Jack o seu entrosamento com a nova realidade. Até ao ponto em que o garoto, que sempre relutou ao fato de cortar o cabelo, pois dizia que sua força nele estava, permite que a avó o faça. Para ele, simbolizou a entrega da sua força à mãe, que permanecia internada e estava precisando fortalecer-se.

Joy sai da condição de internamento e reencontra o filho. Os dois decidem se despedir do quarto em que passaram anos de sua vida e assim fizeram. Na visita ao quarto, Jack nota o quanto ele, que sempre pareceu grande e suficiente para si e sua mãe, agora, após conhecer uma realidade sem limites de dimensão, era pequeno. Ele considera o mundo muito grande. 0 aposento que foi o seu mundo não parece o mesmo com a porta aberta, que propicia a ligação com a "realidade" que o quarto nunca propiciou. Por fim, Jack se despede de tudo, de todos os objetos que para ele tinham nome e vida e que ele conviveu durante seus primeiros cincos anos e, ao final, diz: tchau, claraboia. Logo a claraboia que era o único contato que ele tinha com os reflexos do sol durante o período em que passou confinado com sua mãe. Pablo Villaça (2016, p.4-5) aduz sobre isso:

[...]Da mesma maneira, sua forma de se expressar é peculiar: 'dentro' e 'fora' são conceitos abstratos, já que o exterior não é algo real - e, assim, sua tentativa de compreender o que o cerca acaba levando-o a confusões como questionar se algo está "de fora do lado de fora". Para Jack, o resto do mundo não é amplo, mas, no máximo, um aposento vizinho no qual certamente não há espaço para caber tudo que sua mãe descreve existir fora de seu alcance. Mas talvez o mais fascinante na lógica narrativa concebida por Abrahamson e sua equipe seja mesmo a forma como levam o espectador a perceber como Jack enxerga o quarto: na primeira metade da projeção, que se concentra naquele minúsculo espaço, o cineasta emprega lentes com maior distância focal (teleobjetivas) que resultam 
em quadros mais fechados que revelam apenas partes do aposento e que, justapostos através da montagem eficiente, acabam sugerindo uma dimensão bem maior do que a real. Já mais tarde, ao revelar o verdadeiro tamanho daquela 'cela', o diretor adota grandes angulares que conseguem expor simultaneamente paredes opostas, surpreendendo o público com a pequenez do cenário e estabelecendo, consequentemente, como a percepção do próprio Jack agora se ampliou.

Pablo Villaça (2016, p. 4-5), inclusive, na sua crítica ao filme 0 quarto de Jack, ressalta certos pontos, como o fato de que Jack, com apenas cinco anos de idade, julga o seu cotidiano feliz e agradável e não enxerga o espaço em que vive com sua mãe de forma reduzida, até descobrir que aquele quarto configurava uma prisão. Coloca ainda a questão de a idade de Jack facilitar a adaptação dele às novas circunstâncias, como é dito pelo próprio médico no filme. No entanto, para Joy, é mais complexo, tendo em vista que a liberdade recuperada resultou em novos conflitos: descobrir como viver no mundo "real" após a experiência no quarto de Jack.

A nova realidade de Jack significa para ele o ganho: de novos espaços, novas condições, novas pessoas, novos afetos, novos seres. Já para Joe, o regresso, de início, simboliza essa dimensão perdida por sete anos, o estranhamento, o sentimento de inaptidão. 0 ganho na exposição; a perda no regresso, são dimensões interessantes de se explorar. Mas se focará, propriamente, na primeira: a exposição ao novo como etapa elementar à vivência do processo de "ser" humano.

\section{OS PONTOS COMPARATIVOS ENTRE A ALEGORIA DA CAVERNA DE PLATÃO E O FILME O QUARTO DE JACK}

As duas obras utilizam-se de imagens pelas quais se pode refletir uma mesma questão: as diferentes perspectivas do que seja o Real. Platão insiste que há um real, cujo conhecimento se alcança com a racionalidade. Que é necessário sair do confinamento das sombras e buscar a luz, que possibilita o conhecimento da verdade: o contato com a realidade, com a completude do objeto. Já "O quarto de Jack”, se é mais benevolente quanto à única 
verdade, revela-se bem mais pungente quanto à restrição espacial, ao tratar da "realidade" do mundo pela perspectiva com a qual se o habita e vive.

Ricos em enquadramentos, o espaço ou a dimensão geométrica é o ethos no qual se trata a realidade. Cheios de simbolismos, as duas obras permitem comparações que merecem ser explicitadas para que se compreenda o "real" na vida de uma pessoa. Em um primeiro momento, a similitude óbvia: tanto na alegoria da Caverna de Platão, como no filme o Quarto de Jack, as pessoas confinadas a um espaço limitado são prisioneiras. No caso de Jack a comparação leva à identidade, pois a criança nasceu prisioneira e assim permaneceu até os cinco anos.

Um outro ponto cenográfico de similitude consiste no fato de que, se na obra de Platão os presos tinham como iluminação a fogueira acesa exteriormente à caverna, que nela permeava por meio de uma abertura, no filme "O quarto de Jack", a mãe e o filho, também aprisionados, através da luz solar ou lunar que entra pela claraboia, têm acesso à realidade fora do quarto. As duas aberturas funcionam como comunicação com o espaço existente para além dos limites físicos das prisões, que são, respectivamente, uma caverna e um quarto.

Acrescenta-se, ainda: a luz que entrava por meio da abertura na caverna produzia sombras, compreendidas pelos prisioneiros como a única realidade, pois apenas por esta iluminação indireta se conhecia a forma das coisas exteriores à caverna. Pois estas sombras, projetadas na caverna, desempenham papel semelhante às imagens da televisão que o Jack assistia, que as compreendia, de acordo com o relato da mãe, umas como realidade e outras não. Tanto Jack como os prisioneiros na caverna tinham a necessidade de nomear: estes, as sombras, aquele, as coisas que tinha conhecimento através da narrativa materna. A visão de Pedro Calabrez (A ALEGORIA... 2017), abordada no vídeo contextualiza bem a referida situação:

0 ato de dar nomes, nomear as coisas é algo muito comum as crianças, por exemplo. Por envolver uma tentativa de dar sentido a realidade que está a nossa frente, ou seja, um dos principais passatempos, no fundo da caverna, é nomear coisas em uma espécie de jogo entre nós para ver quem acerta ou quem erra os nomes das sombras projetadas na parede. E o conhecimento, a sabedoria lá no fundo da caverna é saber o maior número 
possível de nomes para aquelas coisas. Aliás, nós não sabemos que aquilo são sombras, porque acreditamos que aquilo é o mundo real. Afinal, nós nunca vimos algo diferente daquilo. Ou seja, as sombras são a verdade, porque nunca tivemos conhecimento de outra verdade que não aquela.

Talvez o ato de nomear as sombras pelos prisioneiros seja uma advertência de Platão para o engodo das palavras, uma antecipação crítica ao nominalismo, a desconfiança de que a dimensão linguística, que se enquadraria no mundo do sensível, em nada revela a verdade, que demanda a racionalidade pura. Já para Jack, é uma forma de compreender, apreender, significar os objetos escassos e ímpares do seu mundo, que alcançam importância superior aos objetos de um mundo ilimitado. Em um mundo pequeno, de lentas e poucas distrações, nomear atende à sensibilidade humana carente de valoração.

Em um outro ponto fundamental as duas histórias se comunicam: na alegoria da Caverna, quando um dos prisioneiros é liberto e volta para dialogar sobre a nova perspectiva que adquiriu da realidade com os seus antigos companheiros, por eles é desprezado, já que, há muito tempo, têm a sua verdade como imutável, de maneira que não é imediata a mudança do entendimento. De forma muito parecida ocorre quando Joy revela a Jack que o quarto que ele sempre viveu bem e, formidavelmente, até feliz, por ser a única realidade por ele conhecida, era, na verdade, uma prisão. Jack, assim como os prisioneiros da caverna, tende a rejeitar a ideia proposta por sua mãe.

0 garoto, como o prisioneiro liberto, ao conhecer a verdade, da mesma forma que acontece na alegoria da caverna, tem um processo também dificultoso em aceitar a nova perspectiva de realidade. Para o menino de apenas cinco anos, conceber que as coisas poderiam ter mais de uma dimensão e que não se resumiam ao mundo vivido por ele e por sua mãe no quarto foi, no mínimo, assustador. Para isso, precisou soltar as amarras da percepção de acordo com a qual há muito tinha sido programado pelo relato materno. Mas ao contrário de Platão, no qual a racionalidade, ao levar à verdade, é suficiente à abertura para um novo mundo, no filme a adaptação é motivada, em especial, pelos afetos: à media que a criança passa a confiar no afeto da avó, do padrasto da mãe, no do cachorro, ele vai se legitimando ao "novo" mundo. 
A metáfora da caverna e o a filme também se assemelham na intuição de que o conhecimento de uma nova dimensão da realidade muda as pessoas. Do mesmo jeito que o prisioneiro da caverna, ao ser liberto, passa a desprezar o conhecimento anterior que tinha, Jack muda seu posicionamento com relação ao quarto; inclusive, quando o vai visitar, dá-se conta da sua real dimensão diminuta. 0 conhecimento de uma outra realidade faz com que o garoto tenha nova visão e ressignifique as coisas que compunham sua anterior realidade.

Por fim, uma última similitude: no mito da caverna de Platão, a dicotomia entre o mundo visível e o mundo inteligível: o primeiro é o mundo que, por ser acessível aos sentidos, a um primeiro momento crê-se como realidade, não obstante o segundo, disponível à racionalidade, ser o verdadeiro. Já no filme "O Quarto de Jack", tem-se como o mundo visível o quarto, quando ainda não revelado ao menino como prisão. 0 mundo inteligível, por sua vez, apresenta-se com a expansão da perspectiva de Jack sobre o mundo, que se inicia pelos relatos da mãe e se completa com o contato direto com os novos espaços, objetos, seres e pessoas.

Mas nos dois, o confinamento surge como limitador, do corpo, da alma, da vida, do processo de "ser" humano: a exposição ao novo, a uma nova perspectiva geográfica, afetiva, estética, cognitiva, a remodelar padrões de percepções e as próprias percepções, a desenvolver novas e insuspeitas funcionalidades e capacidades, a explorar o humano, que precisa ser exercitado.

\section{A EXPOSIÇÃO COMO CRITÉRIO DE POLÍTICA PÚBLICA EDUCACIONAL NO CONSTITUCIOLISMO CONTEMPORÂNEO BRASILEIRO}

As duas histórias falam da exposição a uma outra dimensão, utilizandose, conforme o já ressaltado, uma linguagem espacial: do confinamento interior ao ilimitado exterior, para simbolizar o desenvolvimento epistemológico, no caso da caverna, mas também afetivo, no quarto do Jack. Quando se sai da caverna e enxerga-se as coisas mediante a luz do sol, se as vê por outra perspectiva e percebe-se que a anterior 
é apenas parcial. Quando, por outro lado, se utiliza de um microscópio para analisar tecidos e células, alcança-se outra dimensão e verifica-se que a anterior não era completa. Por estes exercícios de ficção literária, se chega à conclusão de que, seja para se descobrir a verdade, seja por uma questão de obter-se conhecimento mais completo e informado, fazse necessária a exposição a diferentes ângulos ou dimensões pela qual se analisa o objeto.

Mas para além da perspectiva epistemológica de conhecimento do objeto, há, em especial, o caráter pessoal: o desenvolvimento da pessoa pela exposição a novas dimensões de realidade. 0 quarto do Jack assim o fez: a vida que se dá por espaços que se comunicam. Espaços ilimitados, em que um menor está contido em um maior: um quarto em um quintal, que se abre para a rua, da qual se sai para o interior de um jardim, que termina na porta de uma casa, com quartos que se delimitam e integram por portas.

A exposição a diferentes planos permite conhecer novos mundos e, por uma dimensão pessoal, permite escolhas mais adequadas ao indivíduo. Neste preciso ponto, abordam-se os conceitos de auto respeito e autenticidade que Ronald Dworkin (2011) trabalha como deveres morais elementares à dignidade humana: o homem tem o dever de levar a sua vida a sério, ou seja, não deve tratar como oportunidade apta ao desperdício, e assim o faz quando constrói uma narrativa de vida coerente aos seus valores essenciais. A autenticidade, por outro lado, é uma empreitada personalíssima, que se faz tanto e mais adequadamente à medida que se possibilita uma maior exposição do indivíduo às diferentes dimensões da vida. É o que se faz quando se o permite sair da caverna e conhecer as coisas iluminadas, diretamente, pela luz solar, ou quando se abre a porta do quarto e se comunica com o jardim, que se comunica com a rua, que se comunica com outro quarto. Abrem-se novas possibilidades que, de início, são estranhamentos, mas que podem vir a incorporasse a novos planos e projetos de vida que a pessoa venha a compreender como mais pertinentes a si.

A pessoa desenvolve suas potencialidades, sejam cognitivas e afetivas, mediante a exposição. A vida como um processo de exposição fora explorada em que o conhecimento de si e do outro e ainda das 
coisas demanda um contínuo processo do status quo ao novo, ou melhor, da exposição ao novo.

O que se quer pincelar de comum é a multidimensionalidade e a sua importância ao desenvolvimento e à autenticidade do ser humano. A capacidade de desenvolvimento, de que trata Amarthya Sem (2009), ou da justa oportunidade de preenchimento de cargos e funções sociais abertos a todos, a qual se refere Rawls (1971), demanda uma política de Estado de acesso a essa multidimensionalidade.

Ainda sobre dignidade humana, vale ressaltar que, na concepção Kantiana (KANT, 2007, p.67-68), esta é fundamentada através do elemento da autonomia da vontade e do critério finalístico, em que neste, o homem é compreendido como sendo um fim em si mesmo. Deste modo, pela soma destes dois fatores expostos, tem-se a efetivação da dignidade para Immanuel Kant.

Por esta perspectiva, se deve compreender o alcance do artigo 227 da Constituição Federal brasileira, que impõe como dever do Estado democrático, da sociedade e da família, prioritariamente, o direito à vida, à saúde, à alimentação, à educação, ao lazer, à profissionalização, à cultura, à dignidade, ao respeito, à liberdade e à convivência familiar e comunitária, às crianças e aos adolescentes, devendo lhes colocar a salvo da situação de negligência, discriminação, exploração, violência, crueldade e opressão (BRASIL, 1988).

Neste sentido, com base no fato de que o ordenamento jurídico brasileiro adotou a proteção integral no que diz respeito ao direito da criança e do adolescente, pode-se afirmar que não cabe apenas ao Estado viabilizar a proteção dos que estão em desenvolvimento, mas também é de responsabilidade da família e da sociedade. Assim, vale ressaltar que a concretização dos direitos fundamentais das crianças e dos adolescentes depende de uma "tríplice responsabilidade compartilhada" (SOUZA; SERAFIM, 2019, p. 212-213).

A Lei no 8.069, de 13 de julho de 1990, que dispõe sobre o Estatuto da Criança e do Adolescente (ECA), no seu artigo $4^{\circ}$ e $5^{\circ}$, está em consonância com o artigo 227 da Constituição Federal brasileira e baseia-se na proteção integral das crianças e dos adolescentes, conforme o artigo $1^{\circ}$ do referido Estatuto (BRASIL. 1990). Nela, merecem destaque os artigos $3^{\circ}$ e o $7^{\circ}$, 
do ECA, o primeiro a assegurar, à criança e ao adolescente, os direitos fundamentais inerentes à pessoa humana, possibilitando-se lhes, por lei ou por outros meios, todas as oportunidades e facilidades, a fim de lhes facultar o desenvolvimento físico, mental, moral, espiritual e social, em condições de liberdade e de dignidade, o segundo a estipular que a criança e ao adolescente têm direito a proteção à vida e à saúde, mediante a efetivação de políticas sociais públicas que permitam o nascimento e o desenvolvimento sadio e harmonioso, em condições dignas de existência (BRASIL, 1990).

Vale ressaltar a necessidade da instituição de políticas sociais direcionadas, de maneira especifica, para tratar das questões referentes a infância e a adolescência por meio do que determina a doutrina da proteção integral. Desta forma, as políticas públicas especificas e voltadas para a efetivação dos direitos das crianças e dos adolescentes são meios democráticos de concretizar o direito positivado (RAMIDOFF, 2016, p. 237-238).

Possibilitar que a pessoa se desenvolva implica exposição crescente às várias dimensões da vida, inclusive cognitivas. Para que se aproprie de si, encontre-se, é necessária uma política pública que trabalhe a educação por esta perspectiva da exposição, o que asseguraria a igual dignidade de todos. Este, entretanto, é um desafio à democracia: primeiro, porque considerar que a igual dignidade se asseguraria por oportunidades equitativas de exposição, de forma que a pessoa possa realizar-se e realizar os seus projetos de vida, pode ser considerado uma teoria compreensiva que implicaria impor uma determinada concepção do bem a todos. Por que se deve ser exposta às novas dimensões e perspectivas para desenvolverse? E se Jack não quisesse ter saído do quarto? E se quisesse ter voltado? E se o prisioneiro liberto preferir o mundo das sombras?

A opção por não se expor não seria possível, em especial às crianças e aos adolescentes, uma vez que o desenvolvimento de suas potencialidades mediante exposições seria fundamental a uma opção informada de meta de vida? São questões que se colocam com força em uma democracia, na qual, por um lado, a igual dignidade convida para se trabalhar conceitos materiais da própria dignidade e igualdade, que envolve capacidade, justa oportunidade e autenticidade, mas, por outro, adverte quanto 
à arrogância da verdade universal e absoluta que se manifesta no paternalismo estatal, tanto mais perigoso quando se esteja diante das pretensões de um Estado-educador.

\section{CONSIDERAÇÕES FINAIS}

0 presente artigo propõe-se a demonstrar, por diferentes narrativas, que a "exposição" ao novo é momento elementar ao processo de "ser" humano. Para tanto, utilizou-se do mito da Caverna, tratado por Platão na República, bem como analisou-se o filme "O Quarto de Jack". O primeiro, para se explorar o efeito do novo à cognição; o segundo, para analisar o impacto do novo sobre afetos, percepções e conhecimentos.

Em ambas as narrativas, tem-se o relato pungente do papel ou da função da exposição no desenvolvimento humano - se é que se possa chamar o processo de vida de desenvolvimento: a incompletude mesquinha e tacanha do conhecimento, a poda de afetos, habilidades e funcionalidades, que ocorrem quando se está fechado/encarcerado em um contexto hermeticamente conservado. $\mathrm{O}$ auto referenciamento turvo que sobressai no ambiente limitado, que não se comunica: a negativa da alienação, que impede o processo de "ser" autentica e ilimitadamente.

Dos exemplos tratados no decorrer do capítulo, propugna-se que a exposição a novas dimensões, cognitivas e mesmo afetivas, são elementares ao processo de ser humano e que devem ser objeto de políticas públicas. Pelo "direito" à "exposição" se deve analisar o dever do Estado, da sociedade e da família para com as crianças e adolescentes por meio das políticas educacionais. A inclusão é uma das facetas da exposição: incluir/expor crianças e adolescentes ao ambiente no que, na normalidade dos casos, dá-se a vida social, profissional, política da pessoa.

Não obstante, ao final, não se pode descurar do paradoxo que essa ideia acerca da exposição traz: ela importa, muito provavelmente, uma concepção do que é o bom e o virtuoso, que num esquema de sociedade democrática desafia a equidade. Aqui, um parêntese: compreende-se a equidade, na constituição e vivência de uma sociedade democrática, como ausência de hierarquia entre os homens. Não obstante, a ideia de que a 
exposição é um elemento que integra o processo de "ser" humano pode parecer, a alguns ou muitos, a imposição de um modelo de vida boa, que quebraria o igual respeito e consideração pelo governo aos cidadãos.

Mas sem que se apodere de algumas dimensões materiais acerca da dignidade, do "ser" pessoa, elementos essenciais à vivência de uma democracia tornam-se vulneráveis às contingências do real. Uma dimensão exclusivamente formal da igualdade e da liberdade que constituem a dignidade é insatisfatória ao valor da igualdade e da liberdade ao indivíduo e à dinâmica democrática. Ou seja: a igualdade e a liberdade devem ter importância para pessoa e, portanto, impactá-la. Para tanto, é imprescindível que perspectivas materiais do que seja relevante à igualdade e liberdade sejam oficialmente institucionalizadas e tomadas como objeto de políticas públicas, mas sempre sobre a ressalva de que, em algum momento, deve-se resguardar a dimensão formal, que não pode ser substancialmente superada.

\section{REFERÊNCIAS}

A ALEGORIA da Caverna de Platão pelo Prof. Pedro Calabrez.[S.l:s.n]. 2017.1 vídeo (6min $54 \mathrm{seg}$ ). Publicado pelo canal Oficina de Consciências. Disponível em: https://www.youtube.com/watch?v=HqmNb8yZfU4. Acesso em: 08 nov. 2018.

BRASIL. [Constituição (1988)]. Constituição da República Federativa do Brasil. Brasília, DF: Senado, 1988. Disponível em: http://www.planalto.gov.br/ ccivil_03/constituicao/constituicao.htm. Acesso em: 20 out 2018.

BRASIL. Lei $\mathbf{n}^{\circ}$ 8069/90, de 13 de julho de 1990. Brasília, DF: Senado, 1990. Disponível em: http://www.planalto.gov.br/ccivil_03/LEIS/L8069.htm. Acesso em: 08 nov. 2018.

BRASIL. Decreto-Lei $\mathbf{n}^{\circ} \mathbf{2 8 4 8} / \mathbf{4 0}$, de 7 de dezembro de 1940. Brasília, DF: Senado, 1990. Disponível em: http://www.planalto.gov.br/ccivil_03/decreto-lei/ del2848.htm. Acesso em: 08 nov. 2018.

DAMÁSIO, Antônio. A estranha ordem das coisas: A vida, os sentimentos e as culturas humanas. Lisboa: temas e debates; Círculo de leitores, 2017. 
DONOGHUE, emma. Quarto. Tradução vera ribeiro. Campinas, SP: Verus, $1^{\circ}$ Ed, 2011.

DWOKIN, Ronald. Justice for hegerogs. Cambridge: Havard, University Press, 2011.

HANNAH, Arendt. A promessa da política. Tradução. Pedro Jorgensen Jr. Rio de Janeiro: DIFEL, 2008.

KANT, Immanuel. Fundamentação da Metafísica dos Costumes. Tradução de Paulo Quintela - Lisboa: Edições 70, 2007.

MARSOLA, Maurício. A república de Platão. Casa do Saber. 13 jul. 2017. Disponível em: https://www.youtube.com/watch?v=8YBne9Ln_38. Acesso em: 26 out. 2018.

MADRID, Daniela Martins. Do mito da caverna de Platão às "novas prisões" do conhecimento enfrentadas na pós modernidade: a necessidade da libertação. In: ENCONTRO NACIONAL DO CONPEDI, 21., 2012, Uberlândia - MG. Anais[...] Uberlândia - MG: UFG, 2012, p. 1-18. Disponível em http://www.publicadireito. com.br/artigos/?cod=00ec53c4682d36f5. Acesso em: 04 jun. 2018.

MENESCAL, Ana Alice Miranda. A ideia de justiça e a formação da cidade ideal na república de Platão. 2009. Dissertação (Mestrado em Filosofia) Universidade Estadual do Ceará. Fortaleza, 2009. Disponível em: http://www. uece.br/cmaf/dmdocuments/dissertacao_justica_cidade_ideal_platao.pdf. Acesso em: 08 nov. 2018.

NUSSBAUM, Martha. A fragilidade da bondade: Fortuna e ética na tragédia e na filosofia grega. São Paulo; Martins Fontes, 2009.

NUSSBAUM, Martha. Fronteiras da justiça: deficiência, nacionalidade, pertencimento à espécie. Tradução de Susana de Castro. São Paulo: Martins Fontes, 2013.

O QUARTO de Jack. Direção de 0 quarto de Jack. Lenny Abrahamson. NETFLIX. 2016, 1h e $38 \mathrm{~min}$.

ORTENGA, Rodrigo. 0 quarto de Jack' é drama agonizante com olhar infantil de tragédia; G1 já viu: Filme mostra mãe presa em quarto por 7 anos e filho que nasce em cativeiro. 2016. Disponível em: http://g1.globo.com/pop-arte/cinema/ 
noticia/2016/02/o-quarto-de-jack-e-drama-agonizante-com-olhar-infantil-detragedia-g1-ja-viu.html. Acesso em: 08 nov. 2018.

ORGANIZAÇÃO DAS NAÇÕES UNIDAS (ONU). Convenção sobre os Direitos da Criança. Genebra: ONU. 1989. Disponível em http://www.unric.org/html/ portuguese/humanrights/Crianca.pdf. Acesso em: 20 out. 2018.

PLATÃO. A República. 10. ed. Fundação Calouste Gulbenkian. 2007.

QUEIRÓS, Antônio José V. de. Os bastidores da caverna de Platão (entrelinhas de uma alegoria). 0 que nos faz pensar, [S.l.], v. 17, n. 24, p. 95-115, oct. 2008. Disponível em: http://oquenosfazpensar.fil.puc-rio.br/import/pdf_articles/ OQNFP_24_07_antonio_jose_v_de_queiros.pdf. Acesso em: 08 nov. 2018.

RAMIDOFF, Mário Luiz. Infâncias, adolescências e juventudes: direitos humanos, políticas públicas e movimentos sociais. Revista de Direitos e Garantias Fundamentais. Vitória, v. 17, n. 2, p. 219-240, jul./dez. 2016. Disponível em: http://sisbib.emnuvens.com.br/direitosegarantias/issue/archive. Acesso em: 1 ago. 2019.

RAWLS, John. A theory of justice. Cambridge: Havard, University Press, 1971.

SEN, Amartya. A ideia de justiça. Tradução por Denise Bottman e Ricardo Doninelli Mendes. São Paulo: Companhia das Letras, 2011.

SEN, Amartya. The ideia justice. Nassachusetts: Havard, University Press, 2009.

SOUZA, Ismael Francisco de; SERAFIM, Renata Nápoli Vieira. Os direitos humanos da criança: análise das recomendações do comitê dos direitos da criança das nações unidas. Revista de Direitos e Garantias Fundamentais. Vitória, v. 20, n. 1, p. 191-218, jan./abr. 2019. Disponível em: http://sisbib.emnuvens.com.br/ direitosegarantias/issue/archive. Acesso em: 1 maio 2019.

VILLAÇA, Pablo. O Quarto de Jack. Carta Capital. Disponível em: http:// cinemaemcena.cartacapital.com.br/Critica/Filme/8237/o-quarto-de-jack. Acesso em: 26 out. 2018.

Recebido em: 30-08-2019

Aprovado em: 26-10-2020 


\section{Natercia Sampaio Siqueira}

Pós-doutorado em Direito econômico pela Faculdade de Direito da Universidade de Lisboa. Doutorado em Direito Constitucional pela Universidade de Fortaleza (2011. Mestrado em Direito Tributário pela Universidade Federal de Minas Gerais (2002). Graduação em Direito pela Universidade Federal do Ceará (1998). Professora do curso de Pós-graduação (mestrado e doutorado) em direito Constitucional da Universidade de Fortaleza e membro do REPJAL. Atua na área da Teoria da Justiça e Justiça Tributária. É procuradora Fiscal do Município de Fortaleza. E-mail: naterciasiqueira@yahoo.com.br

\section{Camilla Martins Cavalcanti}

Mestre em Direito Constitucional pela Universidade de Fortaleza (UNIFOR), com a Linha de Pesquisa em Direitos Humanos, na Área de Concentração Direito Constitucional Público e Teoria Política (2020). Mestranda acadêmica, na condição aluna especial, do Programa de Pós-graduação em Sociologia da Universidade Estadual do Ceará (UECE) (2019). Diretora e pesquisadora da linha de pesquisa Direito Internacional dos Direitos Humanos do Grupo de Estudos em Direito e Assuntos Internacionais (GEDAI) da Universidade Federal do Ceará (UFC). Membro dos Grupos de Pesquisa: Administração Pública e Tributação no Brasil (GEPDAT) e Relações Econômicas, Políticas, Jurídicas e Ambientais na América Latina (REPJAL), ambos do Programa de Pós-graduação em Direito da UNIFOR. Teve Enunciado Jurídico aprovado para ser debatido, na I Jornada de Processo Civil, feita pelo Superior Tribunal de Justiça (STJ), em agosto de 2017. Graduada em Direito pela Universidade de Fortaleza em 2017. Selecionada pelo seu desempenho acadêmico, como uma dos 10 melhores alunos do Centro de Ciências Jurídicas (CCJ) da Universidade de Fortaleza para participar presencial da palestra do Ex-presidente dos Estados Unidos da América, Bill Clinton, na UNIFOR. Foi monitora da disciplina de Direito de Família na UNIFOR. E-mail: camillam.cavalcanti@outlook.com

Universidade de Fortaleza, UNIFOR

Av. Washington Soares, 1321 - Edson Queiroz,

Fortaleza - CE, 60811-905 